Amaral, T.G., Braga, P.B., and Barros Neto, J.P. 2020. "Application of Dynamic Spreadsheets in the Analysis of Waste by Making-do." In: Tommelein, I.D. and Daniel, E. (eds.). Proc. $28^{\text {th }}$ Annual Conference of the International Group for Lean Construction (IGLC28), Berkeley, California, USA, doi.org/10.24928/2020/0077, online at iglc.net.

\title{
APPLICATION OF DYNAMIC SPREADSHEETS IN THE ANALYSIS OF WASTE BY MAKING-DO
}

\author{
Tatiana G. do Amaral ${ }^{1}$, Pedro B. Braga ${ }^{2}$, and José P. Barros Neto ${ }^{3}$
}

\begin{abstract}
The study of making-do contributes to improvements in the planning and control of construction sites, thus minimizing waste. The present study aims to investigate and analyze waste by making-do in seven companies from Goiás with the aid of a Dashboard and perform the risk analysis of the identified waste. Data were analyzed during technical visits at each site, among which the direct non-participant observation, questionnaire application and document analysis stand out. The analysis of the data indicated that most of waste is related to steps of sealing and structure within the construction sites, in particular, for components connected to plastering and concreting. The main impact of waste by making-do was rework followed by reduced security. The risk analysis was able to identify the main points according to their severity, which guided management and decision making. As final contributions, the main impacts and suggestions to minimize them are presented. Therefore, the aim to study making-do is highlighted in view of its relation with other areas of construction, mainly linked to the quality and safety of construction sites.
\end{abstract}

\section{KEYWORDS}

Waste, making-do, rework, improvisation, dashboard, risk analysis.

\section{INTRODUCTION}

According to Koskela (1992), waste creates an environment where it is possible to reduce waste, reduce costs and increase customer satisfaction, factors considered essential for the competitiveness of companies.

In addition to the seven types of waste identified by Ohno (1998), Koskela (2004) proposed a new waste category, related to the beginning of a task without all its inputs, or when it has its continued execution, even with the assignment of one or more of them, called making-do waste. Bølviken et al. (2014) define making-do as a central waste in construction, as it is the possible cause of other waste.

In Brazil, the waste proposed by Koskela (2004) has been increased in several construction sites. Sommer (2010) associates the theme to improvisations at construction sites and lists the preconditions, categories and impacts arising from it. Leão (2014) and

Professor, Environmental and Civil Engineering. Dept., Universidade Federal de Goiás, Brazil, +55 62981680902, tatianagondim@ufg.br, orcid.org/0000-0002-9746-4025

2 Civil Engineer, Brazil, +55 62 982560737, pedrobraga.engcivil@gmail.com, orcid.org/0000-0002$\underline{3184-1158}$

3 Full Professor, Structural and Civil Construction. Dept., Universidade Federal do Ceará, Brazil, +55 85999691871, barrosneto@gercon.ufc.br, orcid.org/0000-0001-5131-4593 
Santos and Santos, (2017) analyze the waste by making-do relating them to the integrated control of production and quality at construction sites, and to unfinished work and cycle time, respectively.

In Goiânia, the making-do waste survey is part of a research group, in which data were collected from seven construction companies to identify the making-do waste and its impacts (Brandão and Elias 2018, Dinoah et al. 2018, Braga 2018). Due to necessity to work with a larger sample and its difficulties in coding and data analysis, the present work aims to establish a method to identify and analyze waste by making-do through a dynamic spreadsheet to analyze the data dynamically, crossed and simultaneously.

\section{THEORETICAL FRAMEWORK}

\section{DEFINITIONS AND CLASSIFICATIONS OF WASTE}

The concept of waste should be understood as any inefficiency in the use of equipment, materials, labor and capital in larger quantities than those necessary for the construction of the building (Formoso et al. 1997).

According to Shingo (1989), Ohno (1997), Koskela (1992), Formoso et al. 1997, Polat and Ballard (2004), unnecessary activities that generate costs and do not add value to the final product are considered waste.

Soilbelman (1993) states that waste reduction must consider that there is an acceptable level of waste, which can only be reduced through significant changes in the company's technological and managerial development level. Thus, the aforementioned author classifies waste as: a) Unavoidable waste (or natural waste): it corresponds to an acceptable level of waste, in which the investment necessary for its reduction is greater than the savings generated, and; b) Avoidable waste: they occur when the costs of occurrence are substantially greater than the costs of prevention.

Formoso (1997), in turn, proposed eight categories of waste, adding the substitution waste to the seven categories presented by Ohno (1997). The eight categories of waste: by overproduction: production above schedule or before the necessary period; by substitution: use of materials with higher performance than necessary; waiting: long time to start the task, lack of synchronization and balance of the production process, breakage of machines, delay in the delivery of materials (Shingo 1989); by transport: excessive movement of materials or components; by processing itself: performing unnecessary or wrong activities during processing; in stock: unnecessary existence of stocks at high levels; in movement: unnecessary movements made by operators during activities; for the manufacture of defective products: manufacture of products, parts or components that do not meet the specified quality and / or performance requirements.

Shingo (1989) highlights two other types of waste, considered abstractions of the categories mentioned above, which are: work in progress, which falls under overproduction waste; and rework, which falls under processing waste.

Koskela (2004), on the other hand, references the waste from making-do, which are those that occur when a task starts without all its inputs, necessary resources, or when it has its execution continued, even with the assignment of one or more inputs. For the aforementioned author, the term making-do has a negative buffer connotation, that is, it opposes the situation in which the task starts with an excessive stock of available resources. That is, making-do means improvisation, in the sense of performing an activity with what is available. 
For Fireman (2012), making-do can be defined as the reduction in the performance of the productive system due to the execution of activities in suboptimal conditions.

Koskela (2000), Sommer (2010) and Fireman (2012) and Sommer and Formoso (2010), have identified some necessary prerequisites, categories and possible impacts of waste by making-do. Sommer (2010) and Fireman (2012) totaled eight categories of waste by making-do. The following are the categories of waste created by the authors: Access/mobility: related to the space, means or form of positioning of those who perform the tasks; Component adjustments: related to the existence of any unexpected adjustment that is necessary for the use of components or construction elements not suitable for carrying out the tasks; Work area: refers to the work bench or support area during the activities performed; Storage: organization of materials or components in places not prepared to receive them; Equipment/tools: created or adapted for use during activities; Provisional installations: created or adapted for use during activities; Protection: form of use of protection systems; Sequencing: change by the team in the production sequence.

Waste is caused by the lack or poor execution of a set of preconditions or prerequisites necessary to start an activity. Koskela (2000) identified seven items of prerequisites and Sommer (2010) presented a study that grouped some items and created eight other items: Information: adequate information regarding plans, studies or work is not available; Materials and components: activity with quality, quantity and within the design specifications and standards; Labor: the necessary human resources, in number or qualification, is not available; Equipment: is not available, does not work or is not suitable for the tasks; Space: there is no access to the work area, circulation or material storage; Interconnected services: activities with high interdependence compromise the execution of subsequent tasks; External conditions: wind, rain or extreme temperatures; Installations: do not meet the needs for the execution of work packages, including: provisional electrical and hydraulic installations, site security installations, isolation of stock areas, scaffolding and closures.

\section{CAUSES OF WASTE DUE TO MAKING-DO IN CIVIL CONSTRUCTION}

According to Koskela (2004), construction processes involve a large number of inflows, which can be classified into the following categories: design, materials and components, labor, equipment, space, interdependent services and external conditions. The author suggests that problems that are initially disregarded can end up creating obstacles in the progress of tasks. Correct execution of construction planning and anticipating task needs are effective ways to avoid waste from making-do.

Machado (2003) studied the systematic use of managerial anticipations in production planning. For this author, these anticipations would be the result of the experience of previous projects, aiming at providing the necessary resources for the execution of the services.

Thus, so that improvisations do not occur, it is necessary to have minimum conditions for the beginning, development and completion of tasks, which must be obtained through the identification and removal of their prerequisites (Sommer 2010).

\section{IDENTIFICATION AND CLASSIFICATION METHOD OF WASTE BY MAKING-DO}

Santos (2004) proposed an activity concept that, by means of removing restrictions or by management anticipation, brings improvements to a given process. These activities are improvement actions implemented in a given sector to make processes more efficient and effective. According to the author, facilitating activities are those that contribute to avoid 
interruptions in the process. They are related to the concept of continuous improvement and provide a continuous flow of production that reduces the chances of waste due to making-do.

Based on the classification of incoming flows in the construction processes, Sommer (2010) proposed a method for identifying making-do at construction sites. This proposition took into consideration the assumptions of the authors Koskela (2004), Santos (2004), Ballard (2000) and Machado (2003) (Figure 1).

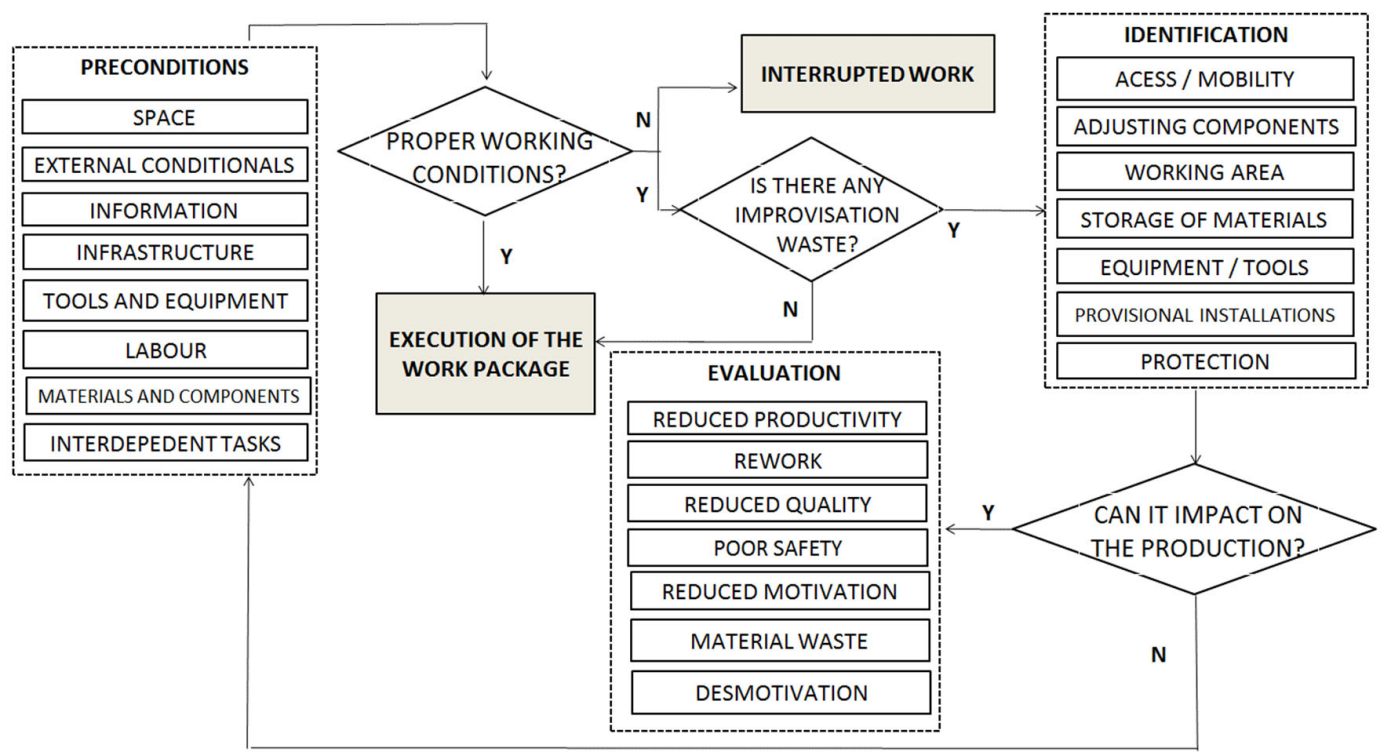

Figure 1: Classification of input flows in construction processes

(Figure in Sommer (2010))

Sommer (2010) determined the preconditions, which, once not met, could cause makingdo, and created seven categories for the classification of making-do. Table 1 shows the categories, preconditions and impacts on production, proposed by Koskela (2000), Sommer (2010) and Fireman (2012).

Table 1: Classification of waste by making-do (Table in Santos and Santos (2017))

\begin{tabular}{|c|c|c|c|c|c|}
\hline $\begin{array}{l}\text { IDENTIFICATION/ } \\
\text { CATEGORY }\end{array}$ & $\begin{array}{l}\text { AUTHO } \\
\text { R }\end{array}$ & $\begin{array}{l}\text { PRE } \\
\text { CONDITION }\end{array}$ & AUTHOR & $\begin{array}{l}\text { IMPACT/ } \\
\text { EVALUATION }\end{array}$ & $\begin{array}{l}\text { AUTHO } \\
\text { R }\end{array}$ \\
\hline Access / mobility & \multirow{7}{*}{$\begin{array}{l}\text { Sommer } \\
(2010)\end{array}$} & Information & \multirow{7}{*}{$\begin{array}{l}\text { Sommer } \\
(2010) \\
\text { Koskela } \\
(2000)\end{array}$} & Low productivity & \multirow{6}{*}{$\begin{array}{l}\text { Sommer } \\
(2010)\end{array}$} \\
\hline Adjusting components & & $\begin{array}{l}\text { Materials and } \\
\text { components }\end{array}$ & & $\begin{array}{l}\text { Decreasing } \\
\text { quality }\end{array}$ & \\
\hline Work area & & Labor & & Rework & \\
\hline $\begin{array}{l}\text { Storage: stock of } \\
\text { materials or components }\end{array}$ & & Equipment / Tools & & Materials waste & \\
\hline Equipment / tools & & Space & & $\begin{array}{l}\text { Compromises } \\
\text { security }\end{array}$ & \\
\hline $\begin{array}{l}\text { Provisional installation: } \\
\text { water and electricity } \\
\text { supply }\end{array}$ & & $\begin{array}{l}\text { Interconnected } \\
\text { services }\end{array}$ & & Demotivation & \\
\hline Protection & & $\begin{array}{l}\text { External } \\
\text { conditions }\end{array}$ & & & \\
\hline Sequencing & $\begin{array}{l}\text { Fireman } \\
(2012)\end{array}$ & $\begin{array}{l}\text { Installations } \\
\text { space } \\
\text { infrastructure } \\
\text { work }\end{array}$ & $\begin{array}{l}\text { Sommer } \\
(2010)\end{array}$ & $\begin{array}{l}\text { Lack of } \\
\text { terminality }\end{array}$ & $\begin{array}{l}\text { Fireman } \\
(2012)\end{array}$ \\
\hline
\end{tabular}




\section{METHOD}

\section{RESEARCH CLASSIFICATION}

An exploratory and descriptive study was carried out, through surveys at construction sites, located to Goiânia/GO, to qualitative and quantitatively identify events that caused waste by making-do.

\section{DATA COLLECTION}

The criteria used for selection of companies were: 1) Interest in participating in academic studies; 2) Having a Quality Management System (QMS) or mapped and monitored processes, allowing access to information such as: plans and their follow-up, verification sheets and services, checklists, among others; 3) Present projects in execution that it is possible to collect data for research. With that, we worked with seven companies, with more than 20 years of experience, of medium and large size and that work mostly with residential buildings for high income. Only one company is not certified and the others have PBQP-h - level A (Brazilian Quality System for Construction) and ISO certifications. The size of the company respected the classification of the Support Service for Micro and Small Enterprises (SEBRAE), which takes into account the number of employees per company. Micro size companies have up to 9 employees, small companies from 20 to 99 , medium companies from 100 to 499 employees and large companies more than 500 employees

The data were collected between July, 2017 and August, 2018 and occurred in all construction sites of the companies participating in the research. After this characterization, we applied structured questionnaires to engineers and supervisors, aiming to investigate waste by making-do related to construction processes and planning. In addition to the questionnaires phase, unstructured interviews were conducted with others technical professional in order to verify documentation, such as designs, list of individual and collective protective equipment, and employee verification and control sheets.

Questions related to project management, production planning and control (Long, Medium and Short-term planning), Supply Chain Management (procurement process, stock control and storage of materials, control of physical space, internal distribution of supplies), Quality Management (Employee Training, Problem Solving, Performance Evaluation, Motivational Policies for Employee Satisfaction).

Photographic records, notes and analysis of drawings and documents were carried out to demonstrate facts and correct classification of waste. With photographic records and notes at the construction sites, at the end of each follow-up, we sought to analyze the drawing associated with these activities in order to prove possible errors of execution, which could cause or influence the identified waste.

For each site visited, we sought to verify the existence of the following documents: schedule, short and medium term planning and service verification sheets.

\section{DATA PROCESSING}

The data collected were organized with the support of Excel software in a spreadsheet (Figure 2). Filling out was done according to the definitions presented in Table 2. From the data collected and classified, these were analyzed using the dynamic spreadsheet Dashboard (Figure 3). 


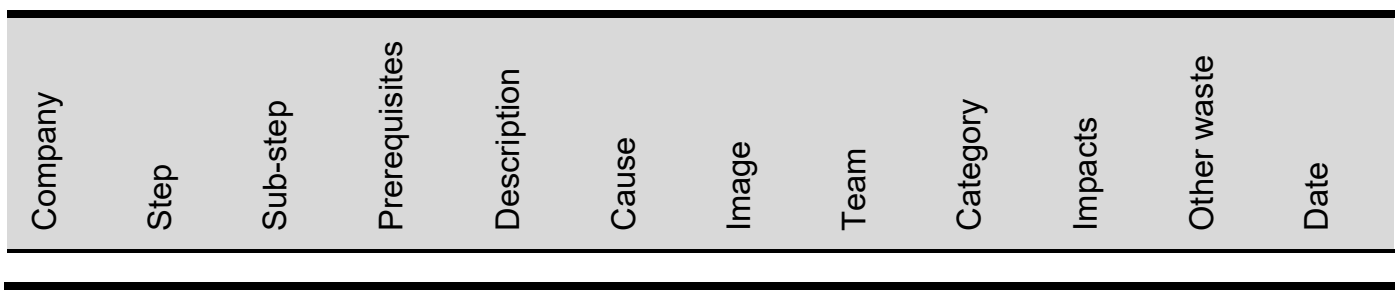

Figure 2: Database model (Source: own authorship (2018))

Table 2: Classification of waste by making-do (Source: own authorship (2018))

\begin{tabular}{|c|c|c|c|}
\hline PRE CONDITIONS & CATEGORIES & IMPACTS & OTHER WASTE \\
\hline Information & Access / Mobility & $\begin{array}{l}\text { Decreased } \\
\text { productivity }\end{array}$ & Substitution \\
\hline $\begin{array}{l}\text { Materials and } \\
\text { components }\end{array}$ & $\begin{array}{l}\text { Adjusting } \\
\text { components }\end{array}$ & Demotivation & Overproduction \\
\hline Labor Work & Area & Materials waste & Waiting \\
\hline Equipment and Tools & Storage & Rework & Processing \\
\hline Space & Equipment / Tools & Reduction of safety & Defective product \\
\hline $\begin{array}{l}\text { Interdependent } \\
\text { services }\end{array}$ & $\begin{array}{l}\text { Installations } \\
\text { provisional }\end{array}$ & Quality reduction & \\
\hline External conditions & Protection & Lack of terminality & \\
\hline Installations & Sequencing & $\begin{array}{l}\text { Cost } \\
\text { Schedule }\end{array}$ & \\
\hline
\end{tabular}

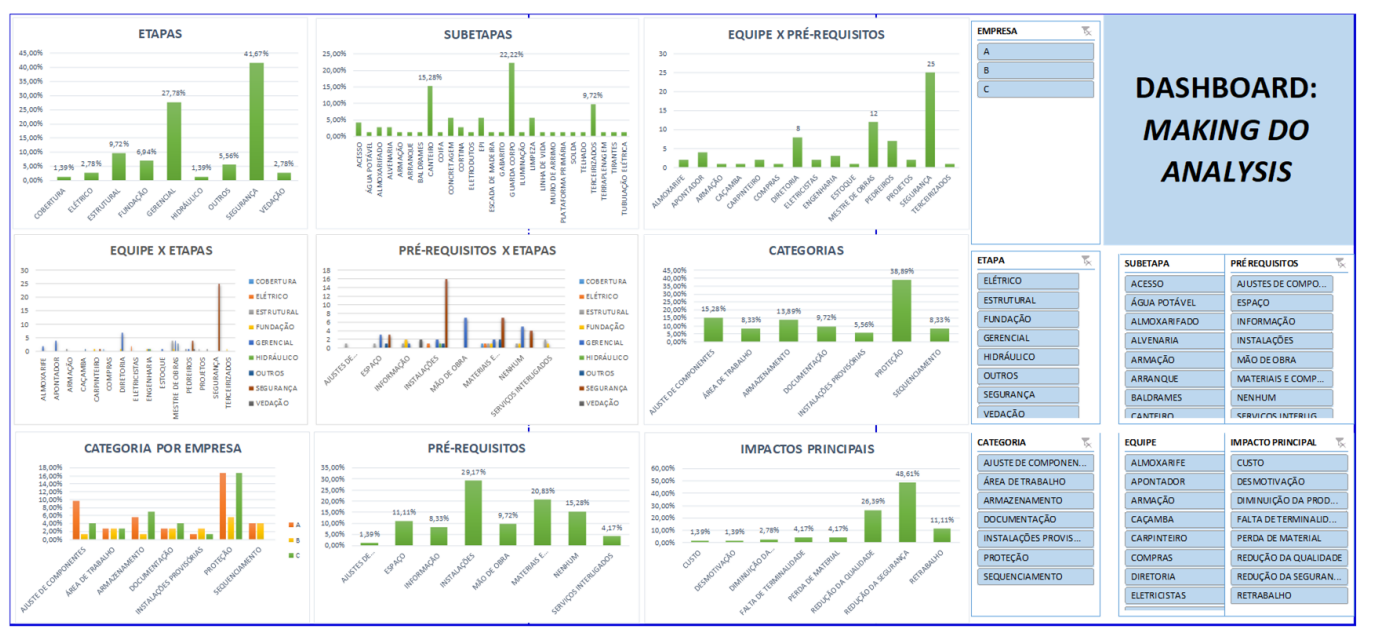

Figure 3: Dashboard model (Source: own authorship (2018))

With the creation of the Dashboard, data were associated simultaneously and instantly, promoting the crossing of information and different analyses in a short period of time. The Dashboard analysis made possible to establish indexes and comparisons for further analysis and definition of guidelines to reduce project waste. At the end, a risk analysis was performed according to parameters defined by Fireman (2012), presented in Table 3. According to Fireman (2012), in the risk analysis the severity of the case and its likelihood of repetition are considered. The method proposed by this author is used in this work and is based on a subjective and qualitative assessment of cases and allows its grouping into three groups: high priority (black), intermediate priority (gray) and low priority (white) (Table 3). 
Table 3: Matrix for risk assessment using severity and probability parameters (Table 2 in Fireman (2012))

\begin{tabular}{|c|c|c|c|c|c|}
\hline PROBABILITY & $\begin{array}{l}\text { SEVERITY } \\
\text { Very High - I }\end{array}$ & High - II & $\begin{array}{l}\text { Moderate - } \\
\text { III }\end{array}$ & Low - IV & Very Low - V \\
\hline A - Unlikely & & & & & \\
\hline $\begin{array}{l}\text { B- Extremely } \\
\text { remote }\end{array}$ & & & & & \\
\hline C - Remote & & & & & \\
\hline D - Probable & & & & & \\
\hline E - Frequent & & & & & \\
\hline
\end{tabular}

The severity criteria "Very High" and "High" were chosen for cases that affected the safety of employees, significantly impacted the budget and schedule of the project and required quick decisions by the management team. The "Moderate" criterion was chosen for failures that did not require immediate decisions or that affected the project's schedule and budget to a lesser extent. The "Low" and "Very Low" criteria were assigned to events with quick and easy resolution and low impact on the project's schedule and budget.

The probability criterion was defined according to the number of occurrences of the failures registered in the researched companies. The cases with high incidence were defined as frequent, those with lower frequency as probable, and the cases with small occurrences were distributed as unlikely, extremely remote and remote according to the criteria exposed above.

As a result of crossing these criteria (Severity and Probability), the level of priority of the collected failures was obtained, namely: high priority, intermediate priority and low priority. With the definition of the priority classification of each case, we proceeded with the calculation of the priority order for each category. This calculation was made by the relationship between the number of cases in each category, for each priority, and the total number of cases in each category.

\section{RESULTS}

The characterization of each construction site visited was carried out considering a description of the site, the number of pavements, the main phases of execution in the study period, the built area, the way in which the labor was hired, the observation period and the expected delivery date of the work. Follow-ups were carried out during the foundation, structure, masonry, installations, frames, plastering phases. Project are singlefamily residential buildings of medium to high standard. The companies have their own and outsourced labor.

Nine projects were monitored and one of them was used as a pilot for the creation of the Dashboard, due to the greater collection of records.

\section{CREATION OF A NEW CATEGORY}

Following the monitoring of the nine projects, 207 making-do occurrences were recorded.

In the work that had the longest follow-up period of the research, it was possible to verify the following contractual failure: start of outsourced activities without the presentation of all necessary labor and safety documentation. We sought to verify at the other construction sites if this contractual failure was frequent, which would justify the creation of a new category of waste by making-do. 
We defined the types of documentation that compose the new category. Labor documentation (contractor's contract, contract between contractor and subcontractors, copy of municipal authorization, employee life insurance, social security certificates, union contribution and company registration card, copies of ID cards) were included in this category, work card, employment contract and employee record sheet) and security (Environmental risk prevention program, occupational health medical control program, PPE card, work order and copies of employees' occupational health certificates).

Also included in this category are machinery and environment operation documentation required for particular services, when performed, such as a portfolio of the Brazilian Institute of the Environment and Renewable Natural Resources (IBAMA), specific function training and others.

\section{RESULTS}

Among all occurrences of making-do recorded in the researched survey, the "sequencing" category stands out, with $41.55 \%$ of the registered cases (Figure 4 ).

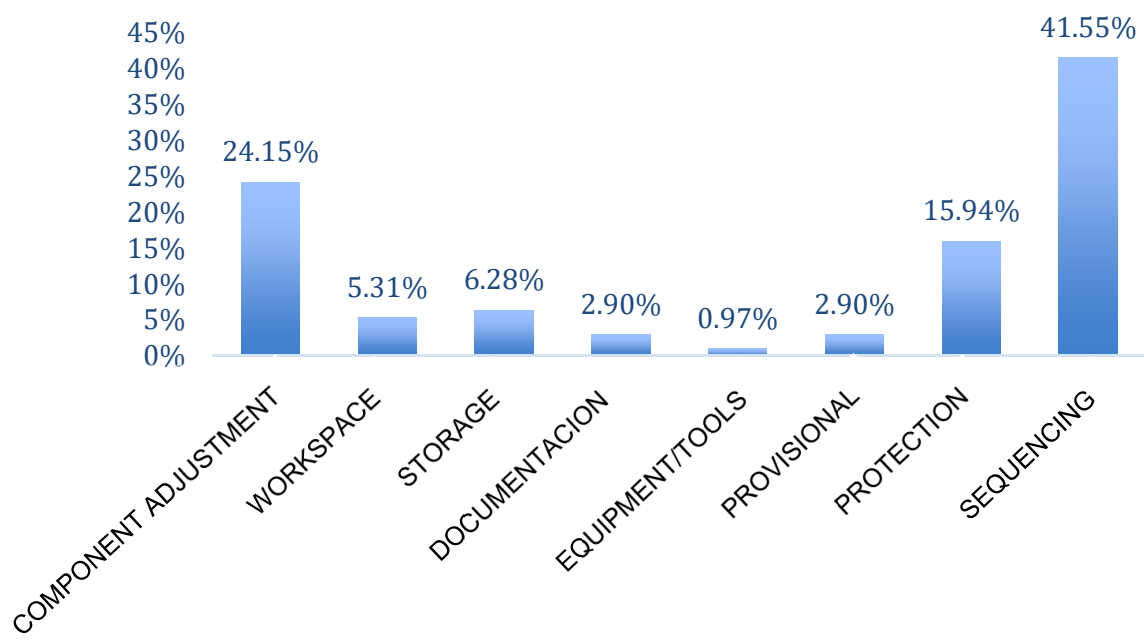

Figure 4: Waste by making-do classified by categories (Source: own authorship (2018))

Sommer (2010) found in his work a value of $56 \%$ for the same category. Registered values are considered high, since these companies have Quality Management Systems (QMS) and have their standardized and monitored processes due to the mandatory implementation of the QMS. It is highlighted that only company A has no certification. The evaluation of the processes related to sequencing shows that there is a greater number of failures in the sub-step "Masonry", as shown in Figure 5. 


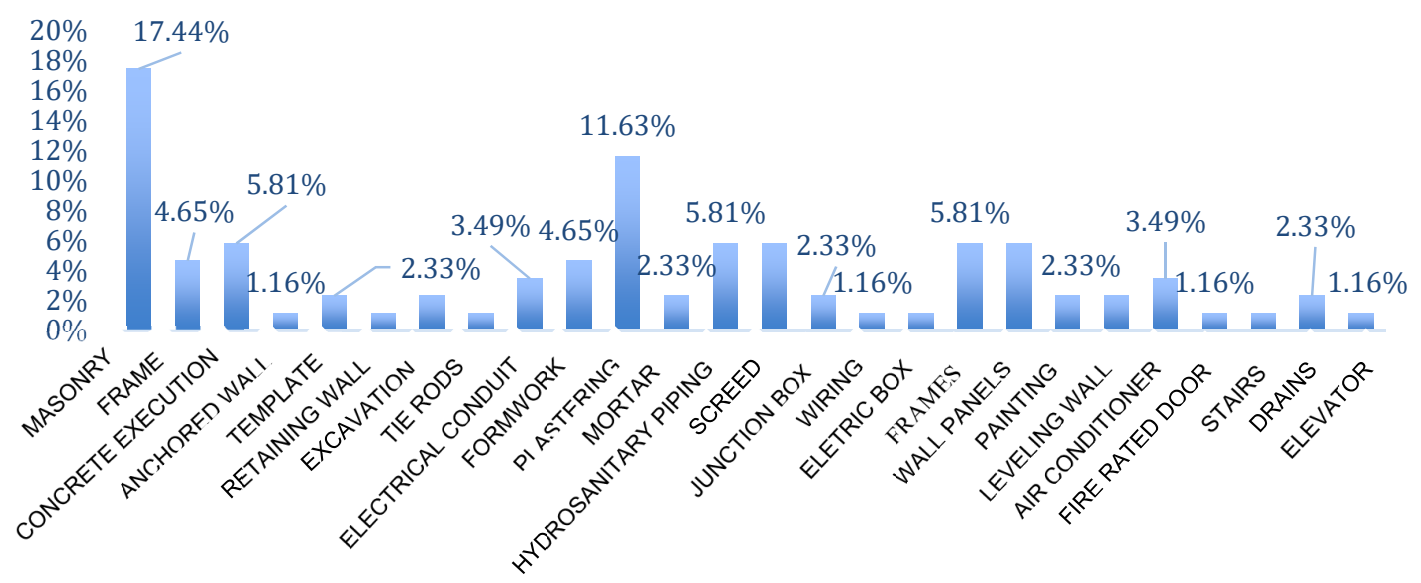

Figure 5: Sub-steps by category

According to the analyses carried out, this item had a higher incidence due to changes in personalized apartments, which were sometimes sent to the construction site late, causing changes in the masonry, which had already been carried out.

Regarding the missing prerequisites, "labor" stood out with $26.09 \%$ of total cases, followed by "information" with $23.19 \%$ of cases (Figure 6).

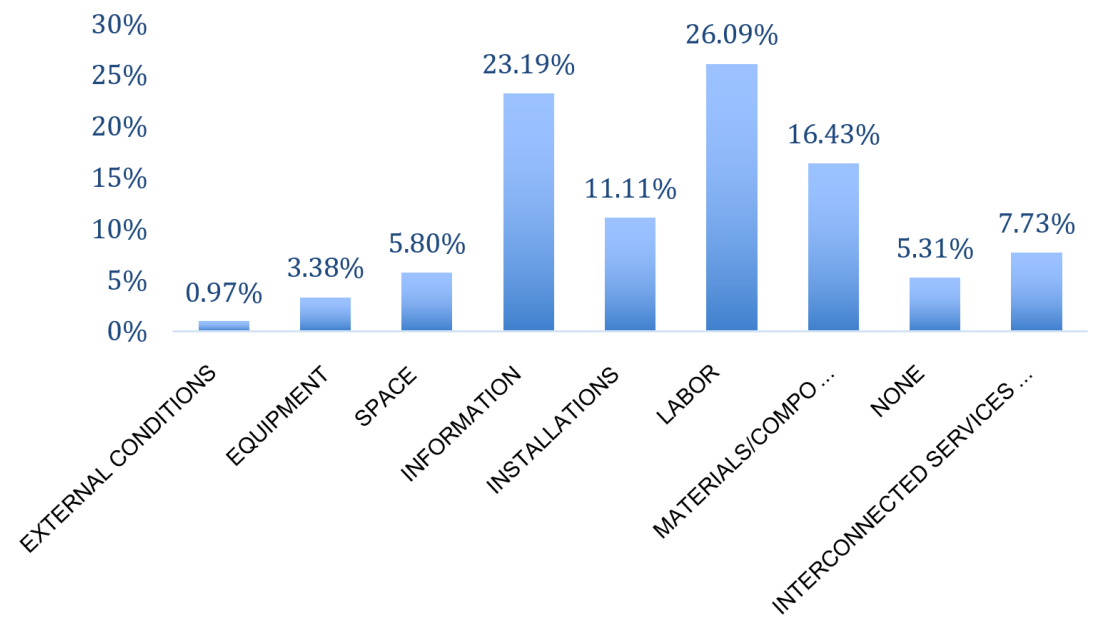

Figure 6: Percentage of prerequisites

This analysis is according to results obtained in relation to the sequencing category, demonstrating that recurrent failures in the communication process (changes in customized apartments, for example) influence directly failures during the execution of masonry.

When analyzing main impacts of the making-do records, the rework was confirmed with $27.05 \%$ of the main impacts generated, followed by the reduction of security, with $23.19 \%$ of the analyzed data (Figure 7 ). 


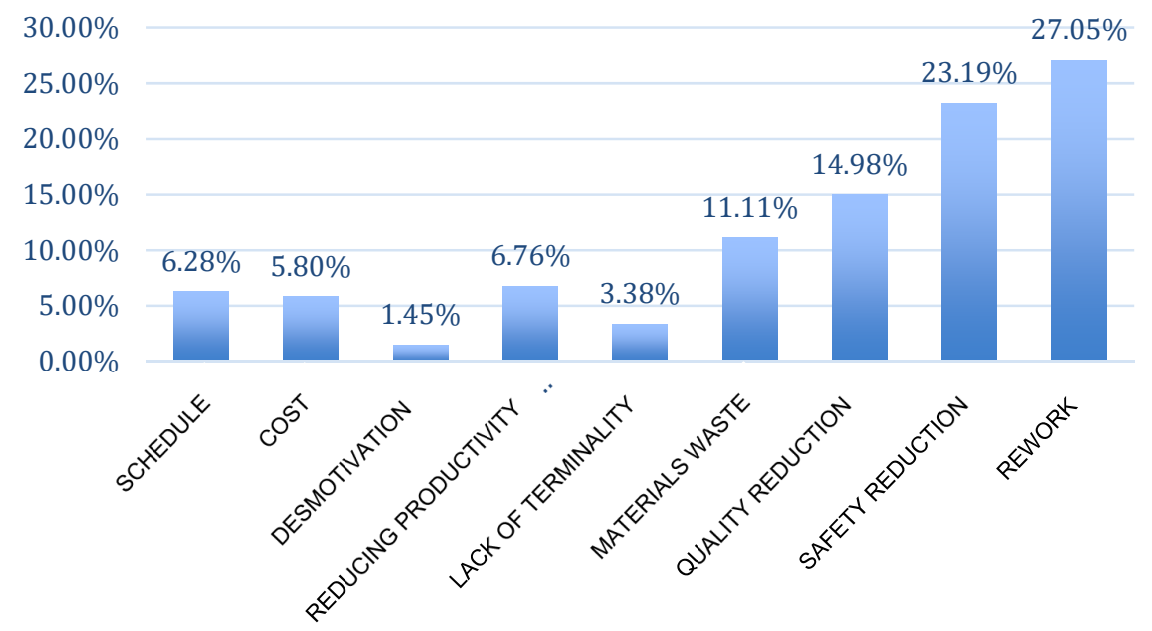

Figure 7: Main impacts

The high rate of rework is directly linked to the ineffective control between the activities present at the construction site, control of projects and their changes and control of execution and non-conformities. The failures of control and inspection of the various processes were the main reasons found to justify this high rate, recorded in practically all stages and sub-steps studied in construction sites. The high rate of safety reduction is due to the inappropriate use of materials as a support for carrying out activities, failures in the use of Personal Protective Equipment and the absence or non-conformity of Collective Protection Equipment.

\section{RISK ANALYSIS}

The occurrences by making-do were classified according to severity and their probability of occurrence (Table 02). Through the experience of researchers and with the help of the work executors, records were also classified according to their probability of occurrence (from improbable to frequent) and according to their severity (from very high to very low). From this correlation, records were classified according to the need for intervention in low, medium and high priority. Considering 207 making-do cases recorded, about 29\% were classified as high priority, followed by $60 \%$ as medium priority, and $11 \%$ as low priority (Figure 8).

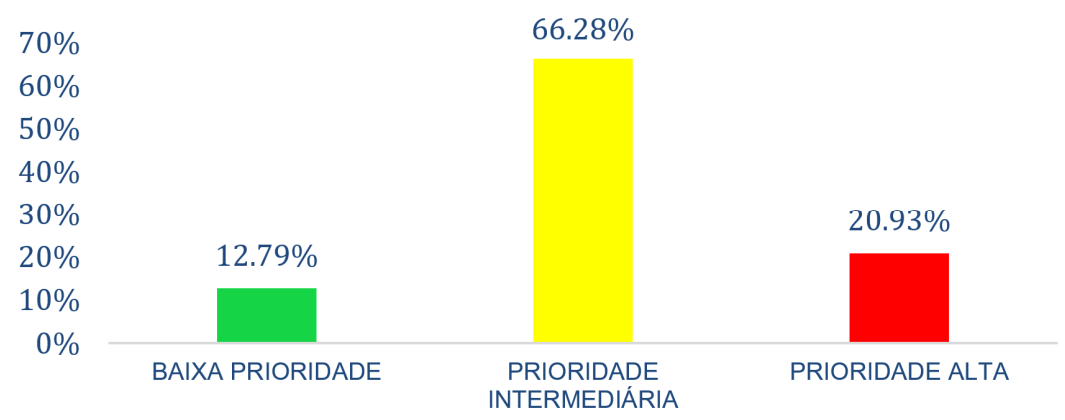

Figure 8: Risk analysis of making-do cases 
Of the steps recorded in the survey, "safety" was the one with the highest number of occurrences that do not have high intervention priority, with around $83.33 \%$ of cases. The records related to "Installations" had a greater need for interventions, with approximately $65.22 \%$ of these cases.

\section{CONCLUSIONS}

The objective of establishing a method to identify and analyze waste by making-do through a dynamic spreadsheet to analyze the data in a dynamic, crossed and simultaneous way was met. The dynamics of the results obtained, using this tool, provides an analysis of the various factors involved in the records collected, serving as a basis for making managerial decisions.

The number of making-do events identified was relatively high in this paper. This occurs in a similar way to the results of previous studies by Formoso et al. (2002), Horman and Kenley (2005), Formoso et al. (2017), that pointed out that the numbers of waste tend to be reasonably high in the construction industry, regardless of the category of waste being investigated.

Also noteworthy is the convergence between previous papers by Brandão and Elias (2018) and Braga (2018), in which sequencing was the category with the highest incidence, followed by component adjustment and protection. Rework and safety reduction were the main impacts of making-do waste of the survey, in conjunction with the results obtained by Sommer (2010), Brandão and Elias (2018) and Braga (2018). Reduction security is highlighted as the high impact with greater risk and need for interventions.

It is noteworthy that situations of records, processes and particularities of each work influence collected data. As result of these factors, it is suggested to expand the sample to other states and analyze them considering construction processes and typologies.

\section{REFERENCES}

Dinoah, L. O., Martins, A. G., Ribeiro, R. G. O. S 2018. Determination of waste by making-do in companies from Goiás. (Monography of Conclusion of Undergraduate Course), Universidade Federal de Goiás, Goiânia, Brazil.

Brandão, C. M., Elias, K. V. 2018. Identification of improvisation waste at construction sites. (Monography of Conclusion of Undergraduate Course). Universidade Federal de Goiás, Goiânia, Brazil.

Braga, P. B. 2018. Analysis of losses by making-do using dynamic spreadsheets. (Monography of Conclusion of Undergraduate Course), Univ. Federal de Goiás, Goiânia, Brazil.

Fireman, M. C. T 2012. Proposed integrated control method between production and quality with measurement of losses by making - do and informal packages. (Dissertation in Civil Engineering), Univ. Federal do Rio Grande do Sul, Porto Alegre, Brazil.

Formoso, C. T., Cesare, C. M., Lantelme, E. M. V., Soibelman, L. 1997. "Waste in civil construction: concepts, classifications and their role in improving the sector." Porto Alegre, Brazil, p. 1-11.

Formoso, C. T., Soibelman, L., De Cesare, C.M., and Isatto, E. L. 2002. "Material Waste in the Building Industry: main causes and prevention." J. of Construction Engineering and Management, 128(4), 316-325. 
Formoso, C. T., Sommer, L., Koskela, L., Isatto, E. L. 2017. "The identification and analysis of making-do waste: insights from two Brazilian construction sites." Ambiente Construído. 17(3), 183-197.

Horman, M., Kenley, R. (2005). "Quantifying Levels of Wasted Time in Construction With Meta Analysis.” J. Construction Engineering Management, 131 (1), 52-61.

Koskela, L. 1992. Application of the New Production Philosophy to Construction. Technical Report $n^{o}$. 72, Center for Integrated Facility Engineering, Stanford University, California.

Koskela, L. 2000. An Exploration into a Theory of Production and its Application to Construction. VTT Publication No. 408, VTT Building Technology, Espoo, Finland.

Koskela, L. (2004). "Making-do - The Eighth Category of Waste." In: $12^{\text {th }}$ Ann. Conf. Int. Group for Lean Construction, Helsingør, Denmark.

Bølviken, T., Rooke, J. and Koskela, L. 2014. "The Wastes of Production in Construction - a TFV Based Taxonomy." In: 22 nd Annual Conference of the International Group for Lean Construction. Oslo, Norway, pp. 811-822.

Leão, C. F. 2014. Model Proposal for Integrated Production and Quality Control Using Information Technology. (Dissertation in Civil Engineering), Universidade Federal do Rio Grande do Sul, Porto Alegre, Brazil.

Machado, R. L. 2003. Systematization of managerial anticipations in planning the production of civil construction systems. (Doctoral thesis in Civil Engineering). Universidade Federal de Santa Catarina, Florianópolis, Brazil.

Ohno, T. 1997. Toyota Production System - Beyond Large-Scale Production. (Editora Bookman), Porto Alegre, Brazil.

Polat, G. and Ballard, G. (2004). "Waste in Turkish Construction: Need for Lean Construction Techniques." In: Bertelsen, S. and Formoso, C. T., $12^{\text {th }}$ Ann. Conf. Int. Group for Lean Construction, Helsingør, Denmark.

Santos, D. de G. 2004. Process management model in civil construction to identify facilitating activities. (Doctoral thesis in Production Engineering), Universidade Federal de Santa Catarina, Florianópolis, Brazil.

Santos, P. R. R., Santos, D. de G. 2017. "Investigation of waste due to unfinished work and its impact on the cycle time of construction processes." Ambiente Construído. (v. 17, n. 2, p. 39-52, abr./jun), Porto Alegre, Brazil.

Shingo, S. 1989. A Study of the Toyota Production System - from an industrial engineering viewpoint. Portland: Productivity Press.

Sommer, L. 2010. Contributions to a method for identifying improvisation waste in construction sites. (Dissertation in Civil Engineering). Universidade Federal do Rio Grande do Sul, Porto Alegre, Brazil.

Sommer, L., Formoso, C. T. 2010. "Making-do waste identification method at construction sites." In: National meeting of built environment technology, p. 10. Canela. 